\title{
Attitudes of women of advanced maternal age undergoing invasive prenatal diagnosis and the impact of genetic counselling
}

\author{
Lea Godino ${ }^{\star, 1}$, Eva Pompilii ${ }^{1,2}$, Federica D’Anna ${ }^{1}$, Antonio M Morselli-Labate ${ }^{3}$, Elena Nardi ${ }^{3}$, Marco Seri ${ }^{1}$, \\ Nicola Rizzo ${ }^{2}$, Gianluigi Pilu ${ }^{2}$ and Daniela Turchetti ${ }^{1}$
}

Despite the increasing availability and effectiveness of non-invasive screening for foetal aneuploidies, most women of advanced maternal age (AMA) still opt for invasive tests. A retrospective cross-sectional survey was performed on women of AMA undergoing prenatal invasive procedures, in order to explore their motivations and the outcome of preliminary genetic counselling according to the approach (individual or group) adopted. Of 687 eligible women, 221 (32.2\%) participated: 117 had received individual counselling, while 104 had attended group sessions. The two groups did not differ by socio-demographic features. The commonest reported reason to undergo invasive tests was AMA itself (67.4\%), while only $10.4 \%$ of women mentioned the opportunity of making informed choices. The majority perceived as clear and helpful the information received at counselling, and only $12.7 \%$ had doubts left that, however, often concerned non-pertinent issues. The impact of counselling on risk perception and decisions was limited: a minority stated their perceived risk of foetal abnormalities had either increased $(6.8 \%)$ or reduced (3.6\%), and only one eventually declined invasive test. The $52.6 \%$ of women expressed a preference toward individual counselling, which also had a stronger impact on perceived risk reduction $(P=0.003)$. Nevertheless, group counselling had a more favourable impact on both clarity of understanding and helpfulness $(P=0.0497$ and $P=0.035$, respectively). The idea that AMA represents an absolute indication for invasive tests appears deeply rooted; promotion of non-invasive techniques may require extensive educational efforts targeted to both the general population and health professionals.

European Journal of Human Genetics (2016) 24, 331-337; doi:10.1038/ejhg.2015.116; published online 27 May 2015

\section{INTRODUCTION}

Women of advanced maternal age (AMA) face an increased risk of having a child affected by a chromosomal disorder such as trisomy 21, 18 or 13 , with the risk rising from 1 in 525 for a 20 -year-old to 1 in 18 for a 45 -year-old woman. ${ }^{1}$ For this reason, in many countries women of AMA have been or still are offered invasive prenatal procedures (IPP), namely amniocentesis (AC) and chorionic villus sampling (CVS), to perform foetal karyotyping. ${ }^{2}$

However, owing to the risk of foetal loss associated with IPP, noninvasive screening tests have been developed and proven accurate in identifying women at increased risk of foetal aneuploidies, regardless of maternal age. The combined test including sonographic measurement of foetal nuchal translucency and the biochemical assessment of free beta-hCG and PAPP-A performed at 11-13 weeks allows detection of $90-95 \%$ of affected foetuses for a false-positive rate of $5 \% .^{3-5}$ Despite the excellent performance of the combined test in antenatal exclusion of trisomy 21, only few countries in Europe have adopted a policy of universal screening of the population and cancelled the AMA as a primary indication to foetal karyotyping. In Italy, according to the most recent guidelines, the combined test is suggested as a primary screening tool in pregnancy, irrespective of maternal age, but the option of IPP is still offered, freely, to women aged 35 or older. ${ }^{6}$ Among the latter group, the large majority uptakes IPP without previous non-invasive screening; recent data show that among a series of 4527 women of AMA attending the Academic Hospital S.OrsolaMalpighi (Bologna, Italy) for prenatal diagnosis, only $534(11.8 \%)$ opted for non-invasive screening. ${ }^{3}$ An increase of non-invasive screening uptake would result in a decrease of IPP and, subsequently, in a reduction of both foetal losses and costs for public health systems. ${ }^{3,4}$ However, in order to pursue such a change, a better understanding of the reasons underlying the choice to undergo IPP is needed. Evidence from the literature ${ }^{7}$ does not enable firm conclusions to be drawn as to the factors influencing the uptake of IPP by AMA women, although a correlation has been suggested with ethnicity, older age and higher education.

Furthermore, a critical issue in the pathway toward IPP is genetic counselling provision. Although genetic counselling has long been proposed as a standard part of all prenatal diagnostic procedures, ${ }^{8,9}$ no clear recommendations existed until 2014, ${ }^{10}$ and in Italy, as well as in other countries, referral for prenatal genetic counselling has been reported to be suboptimal. ${ }^{11}$ There are at least two major goals that genetic counselling may help to achieve in this setting: first, it allows one to accurately ascertain additional genetic risks that may require targeted diagnostic approaches; ${ }^{12}$ second, it ensures that women/ couples receive exhaustive information about meaning, risks and benefits of IPP and support for them in making choices about

\footnotetext{
${ }^{1}$ Unit of Medical Genetics, Department of Medical and Surgical Sciences, University of Bologna; Policlinico Sant'Orsola-Malpighi, Bologna, Italy; ${ }^{2}$ Unit of Obstetrics and Gynaecology, Department of Medical and Surgical Sciences, University of Bologna; Policlinico Sant'Orsola-Malpighi, Bologna, Italy; ${ }^{3}$ Laboratory of Biostatistics, Department of Medical and Surgical Sciences, University of Bologna, Bologna, Italy

${ }^{*}$ Correspondence: Dr L Godino, U.O. Genetica Medica, Dipartimento di Scienze Mediche e Chirurgiche, Policlinico Sant'Orsola-Malpighi Padiglione 11 via Massarenti, 9 , Bologna 40138, Italy; Tel: +39 051 2088425; Fax: +39 051 2088416; E-mail: leagodino@gmail.com

Received 24 January 2015; revised 2 April 2015; accepted 29 April 2015; published online 27 May 2015
} 
prenatal tests. Nevertheless, evidence on the outcomes, as well as on the optimal approach of genetic counselling preceding IPP is extremely scarce. ${ }^{13}$

In recent years, at the Academic Hospital Policlinico S.OrsolaMalpighi, women of AMA undergoing IPP at the Unit of Obstetrics, have been receiving pre-test genetic counselling from the staff of the Medical Genetics Unit. Counselling approach has changed over time because of organization reasons: at first (from January 2010 to June 2011), women/couples used to undergo individual counselling sessions, whereas since July 2011, counselling has been offered in the form of group sessions. Group sessions are preceded by selfadministered questionnaires exploring demographic variables, current/past obstetric history and personal/familial genetic risk factors. Whenever indicated by the questionnaire, which is reviewed by the geneticist prior to the counselling session, individual assessment is arranged. During pre-test counselling sessions, basics of chromosomes and inheritance are provided, then methods, aims and potential results (including false-positive results) of the invasive procedures are extensively discussed (with the use of visual aids in individual sessions and of powerpoint presentations in group sessions). Emphasis is also given to the limitations of the analysis and to the residual risk of foetal anomalies, as well as to the risk of miscarriage associated with the procedures.

Here, we describe methods and results of a cross-sectional survey on a retrospective hospital-based cohort aimed at: (i) exploring reasons for women of AMA to undergo IPP and (ii) investigating the perceived impact of genetic counselling, overall and according to the type of counselling adopted (individual versus group session).

\section{METHODS}

\section{Study design}

In October 2012, we undertook a cross-sectional survey on women of AMA who had undergone genetic counselling and IPP at Hospital S.Orsola-Malpighi, using a mixed-methods design. ${ }^{14} \mathrm{~A}$ cross-sectional survey that included both multiple choice and open-ended questions not only allowed us to collect data on specific issues, but also enabled respondents to provide further information about their views in free-text format.

Two consecutive series of women were identified: all the women counselled in the first semester of 2010 (individual counselling) and all the women counselled in the second semester of 2011 (group counselling), which represented the first semester of adoption of each approach. Women counselled in the first period (individual counselling) formed the group A $(n=473)$; those counselled in the second period (group session) formed the group B $(n=336)$, for a total of 809 women.

\section{Study sample}

Out of the 809 identified women, those with abnormal foetal karyotype or miscarriage and women who eventually underwent IPP in other hospitals were excluded from the study. Thus, 687 eligible women were identified (372 and 315 in groups A and B, respectively) (Figure 1), with a mean age of $38.6 \pm 2.9$ years and a mean gestational age of $81.9 \pm 16.9$ days at genetic counselling.

Of the 687 questionnaires mailed, 221 were returned (response rate: $32.2 \%$ ). Of responders, 117 belonged to group A and 104 to group B (Figure 1). The response rate was not significantly different between groups ( $P=0.682$, Fisher's exact test). Responders did not differ from non-responders with respect to mean age $\left(38.8 \pm 2.7\right.$ versus $38.5 \pm 2.9$ years, respectively; $\chi^{2}=0.18, \mathrm{df}=1$, $P=0.668)$, mean gestational age $(81.0 \pm 17.0$ versus $82.3 \pm 16.9$ days, respectively; $\chi^{2}=1.03, \mathrm{df}=1, P=0.309$ ) and type of IPP (CVS $61.5 \%$ versus $\mathrm{AC}$ $55.8 \% ; P=0.161$, Fisher's exact test), while there was a difference in response rate by nationality, with 220 out of $650(33.8 \%)$ responders among eligible Italian women and only 1 out of $37(2.7 \%)$ among non-Italian women $(P<0.001$, Fisher's exact test $)$.

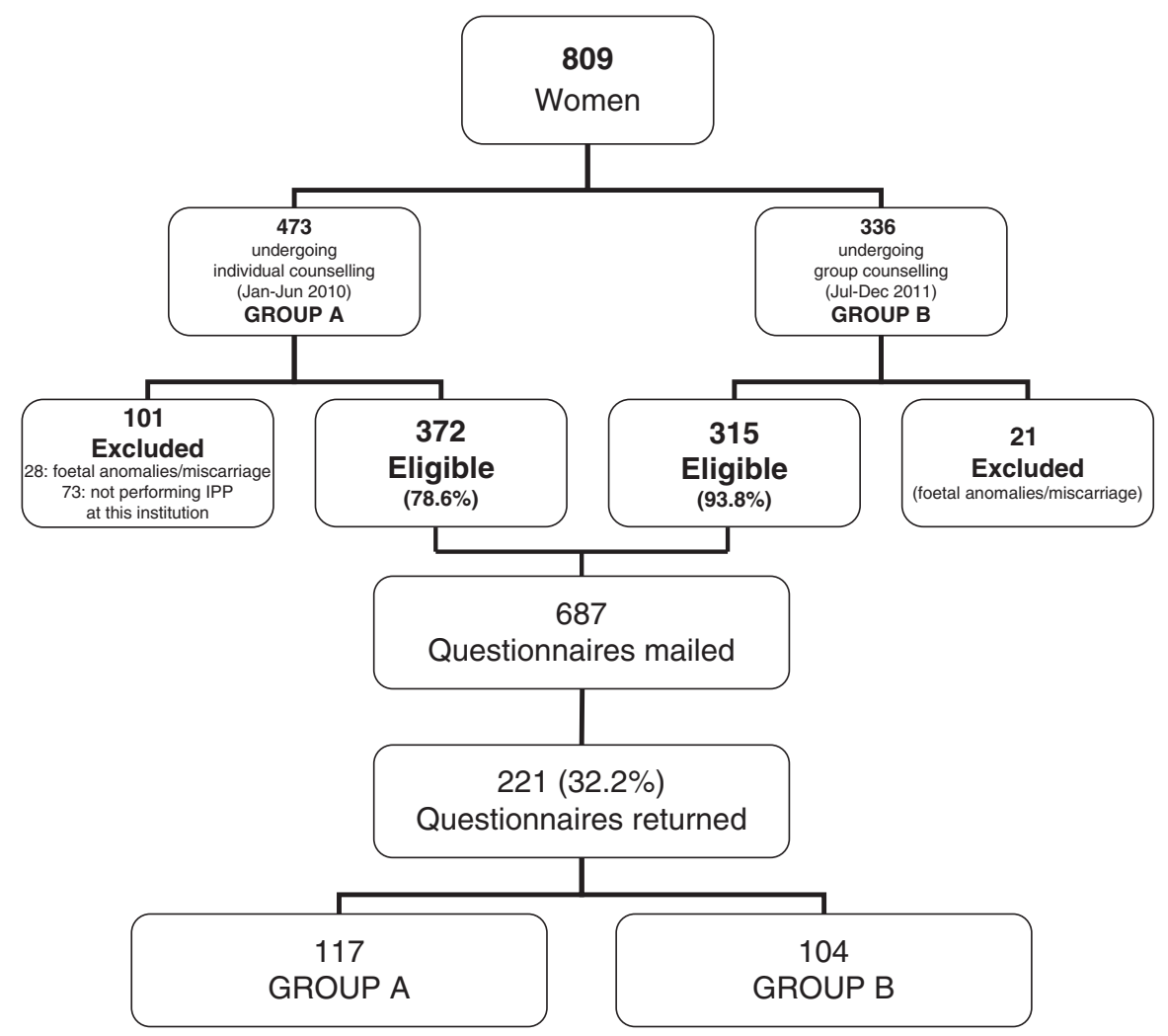

Figure 1 Flowchart of the recruitment process. 


\section{Data collection}

An ad hoc self-administered questionnaire was developed by the authors in Italian language (an English version is available in Supplementary materials). The questionnaire included socio-demographic data and both multiple-choice and open-ended questions for a total of 10 main items and 5 sub-items (explaining the corresponding main item), assessing the following domains: reasons for IPP uptake; perceived clarity and helpfulness of the information received (on a 5-point Likert scale); perceived impact of counselling on: knowledge, risk perception and expectations about IPP; sharing of the information with partner and/or other relatives. The questionnaire was sent to the home address of each eligible woman within a package including an invitation letter, the participant information sheet, the consent form and a prepaid envelop to return the filled forms to the investigators. Questionnaires were mailed in the period December 2012-April 2013.

\section{Ethical considerations}

The study protocol conforms to the ethical guidelines of the WMA Declaration of Helsinki and was approved by the Ethical Board of Hospital S.OrsolaMalpighi, Bologna, Italy (198/2012/O/OssN, 9th October 2012). All women were informed about the purpose and the methods of the study via a participant information sheet. They were informed that they were free to participate or not, with no need to give a reason for declining, and that only questionnaires sent together with a signed consent form would be processed. Moreover, they were asked to fill the questionnaire anonymously to protect their confidentiality.

\section{Data analysis}

Data were entered anonymously into a dedicated database and were analysed by using the statistical package IBM-SPSS Statistics (Ver. 21 for Windows, IBM Co., Armonk, NY, USA). Free text was analysed by content analysis to identify major themes. The women's answers were coded independently by two authors (FD, LG), recurrent themes were identified, and agreement reached through discussion with another author (DT) whenever needed. The themes identified were organised into nominal variables. Mean, standard deviation (SD), ranges and frequencies were used as descriptive statistics. The Kruskal-Wallis one-way analysis of variance by ranks was applied to scale and ordinal variables, the Pearson chi-squared to nominal variables and the Fisher's exact test to dichotomous variables. Two-tailed $P$ values less than 0.05 were considered statistically significant.

\section{RESULTS}

\section{Participants' features}

Demographic data of responders are shown in Table 1: mean age at counselling was 38.8 years (range 35-47); no significant differences were found between groups $\mathrm{A}$ and $\mathrm{B}$ with respect to age, education and daily work. The difference in the age at questionnaire is to be attributed to the earlier period of counselling in group A (first semester of year 2010) in comparison with group B (second semester of 2011). Conversely, as shown in the table, differences between group $\mathrm{A}$ and $\mathrm{B}$ were observed in mean gestational age, and, near to the significance level, in type of IPP, which are probably related to organization changes during the transition from individual to group counselling (increased time interval between IPP request and counselling session; increased number of CVS procedures available). A difference in the type of IPP undertaken was also shown across different age strata, with women aged 40 and older being more likely to undergo CVS than younger women $(60 / 82,73.2 \%$ versus $76 / 139$, $54.7 \%$; $P=0.007$, Fisher's exact test), which is likely due to the priority accorded to older women. Actually, such difference was especially relevant in group A, where $36 / 78,46.2 \%$ younger versus $29 / 39,74.4 \%$ older underwent CVS $(P=0.005$, Fisher's exact test), whereas the difference was not significant in group B (40/61, 65.6\% younger women undergoing CVS versus $31 / 43,72.1 \%$ older women; $P=0.527$,
Table 1 Features of participants

\begin{tabular}{|c|c|c|c|c|}
\hline Sample characteristics & $\begin{array}{c}A / l \\
(n=221)\end{array}$ & $\begin{array}{l}\text { Group A } \\
(\mathrm{n}=117)\end{array}$ & $\begin{array}{l}\text { Group B } \\
(\mathrm{n}=104)\end{array}$ & $\mathrm{P}$ value \\
\hline Age at GC (years); mean $\pm S D$ & $38.8 \pm 2.7$ & $38.7 \pm 2.7$ & $38.9 \pm 2.8$ & $0.568^{a}$ \\
\hline $\begin{array}{l}\text { Gestational age at GC (days); } \\
\text { mean } \pm \text { SD }\end{array}$ & $81.0 \pm 17.0$ & $78.3 \pm 17.0$ & $84.0 \pm 16.6$ & $0.005^{a}$ \\
\hline $\begin{array}{l}\text { Age at questionnaire (years); } \\
\text { mean } \pm S D\end{array}$ & $40.7 \pm 2.8$ & $41.1 \pm 2.8$ & $40.2 \pm 2.7$ & $0.012^{\mathrm{a}}$ \\
\hline \multicolumn{5}{|l|}{ Education } \\
\hline Middle school & $11(5.0 \%)$ & $4(3.4 \%)$ & $7(6.7 \%)$ & \\
\hline High school & $76(34.4 \%)$ & $45(38.5 \%)$ & $31(29.8 \%)$ & $0.628^{a}$ \\
\hline University & 97 (43.9\%) & 49 (41.9\%) & $48(46.2 \%)$ & \\
\hline Post-graduate & 37 (16.7\%) & $19(16.2 \%)$ & $18(17.3 \%)$ & \\
\hline \multicolumn{5}{|l|}{ Daily work } \\
\hline Worker & $5(2.3 \%)$ & $4(3.4 \%)$ & $1(1.0 \%)$ & \\
\hline Employee/Health professional & 159 (71.9\%) & $84(71.8 \%)$ & $75(72.1 \%)$ & $0.449^{b}$ \\
\hline Artisan/Business owner & $5(2.3 \%)$ & $4(3.4 \%)$ & $1(1.0 \%)$ & \\
\hline Manager/Freelance & $40(18.1 \%)$ & $20(17.1 \%)$ & $20(19.2 \%)$ & \\
\hline Unemployed/Homemaker & $12(5.4 \%)$ & $5(4.3 \%)$ & $7(6.7 \%)$ & \\
\hline \multicolumn{5}{|l|}{ Type of IPP } \\
\hline CVS & $136(61.5 \%)$ & $65(55.6 \%)$ & $71(68.3 \%)$ & $0.054^{c}$ \\
\hline$A C$ & $85(38.5 \%)$ & $52(44.4 \%)$ & $33(31.7 \%)$ & \\
\hline
\end{tabular}

Abbreviations: AC, amniocentesis; CVS, chorionic villus sampling; GC, genetic counselling; IPP, invasive prenatal procedures; SD, standard deviation.

aKruskal-Wallis one-way analysis of variance by ranks.

bPearson chi-squared test.

${ }^{\mathrm{c}}$ Fisher's exact test.

Fisher's exact test), because of the increased availability of CVS reported above.

\section{Reasons to undergo IPP}

The first item of the questionnaire was an open-ended question exploring the reasons underlying the choice to undergo IPP. All the 221 participants gave at least one reason, $54(24.4 \%)$ gave two reasons and four women $(1.8 \%)$ three reasons, for a total of 283 responses. The responses and their frequencies are shown in Figure 2. AMA itself was the most frequent reason, given by $149(67.4 \%)$ women $(52.7 \%$ of responses), with 102 women (46.2\%) reporting AMA as the only motivation. Fifty-eight women $(26.2 \%)$ stated they aimed at excluding chromosomal abnormalities ( $20.5 \%$ of responses). The gynaecologist's recommendation was reported as a motivation by 28 women $(12.7 \%$ of women, $9.9 \%$ of responses), with six of them (21.4\%) reporting gynaecologist's recommendation as the only motivation. Twenty-four women reported reasons related to personal experiences (history of foetal anomalies in the family or in previous pregnancies, assisted reproductive technology, twinning or gynaecological diseases), most of which $(n=10,40.0 \%)$ were not actually associated to an increased risk of abnormal foetal karyotype. Twenty-three women $(10.4 \%$; $8.1 \%$ of responses) reported the possibility of making an informed choice about pregnancy as an additional reason; among those, 15 did not explain what decision they should make, while 8 expressed the definite willingness of terminating the pregnancy in case of abnormal karyotype.

We then sought to determine whether socio-demographic features may influence the reason to undergo IPP; younger women were significantly more likely to justify IPP with the desire to exclude chromosomal abnormalities (44/139, $31.7 \%$ versus $14 / 82,17.1 \%$; 


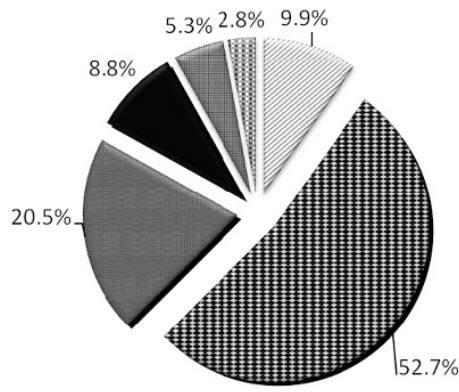

\author{
$\triangle 4$ Gynaecologist's recommendation \\ Advanced maternal age \\ To exclude chromosomal abnormalities \\ - Personal/family experiences \\ 国 To make an informed choice about pregnancy \\ : To terminate pregnancy in case of abnormal karyotype
}

Figure 2 Reasons reported for IPP uptake. The percentage has been calculated on the total of answers (283), as some women have reported more than one reason.

Table 2 Perceived clarity and helpfulness in women undergoing individual (group A) and group (group B) counselling

\begin{tabular}{|c|c|c|c|c|}
\hline & $A / l(\mathrm{n}=221)$ & Group $A(n=117)$ & Group $B(\mathrm{n}=104)$ & P value ${ }^{a}$ \\
\hline \multicolumn{5}{|c|}{ Was the information received clear? } \\
\hline Extremely & 34 (15.4\%) & $18(15.4 \%)$ & 16 (15.4\%) & 0.0497 \\
\hline Very & $137(62.0 \%)$ & $64(54.7 \%)$ & $73(70.2 \%)$ & \\
\hline Quite & $49(22.2 \%)$ & $34(29.1 \%)$ & $15(14.4 \%)$ & \\
\hline Little & $1(0.5 \%)$ & $1(0.9 \%)$ & 0 & \\
\hline Not at all & 0 & 0 & 0 & \\
\hline \multicolumn{5}{|c|}{ Was the information received helpful? } \\
\hline Extremely & $2(0.9 \%)$ & $13(11.1 \%)$ & $11(10.6 \%)$ & 0.035 \\
\hline Very & $68(30.8 \%)$ & $58(49.6 \%)$ & $69(66.3 \%)$ & \\
\hline Quite & $127(57.5 \%)$ & $44(37.6 \%)$ & $24(23.1 \%)$ & \\
\hline Little & $24(10.9 \%)$ & $2(1.7 \%)$ & 0 & \\
\hline Not at all & 0 & 0 & 0 & \\
\hline
\end{tabular}

${ }^{a}$ Kruskal-Wallis one-way analysis of variance by ranks.

$P=0.018$, Fisher's exact test) and less likely to invoke AMA itself as a reason for IPP $(87 / 139,62.6 \%$ versus $62 / 82,75.6 \% ; P=0.054$, Fisher's exact test). Another difference was observed between education and 'gynaecologist's recommendation' response: this motivation was reported by $18 / 87(20.7 \%)$ women with undergraduate education, compared with $10 / 134(7.5 \%)$ women of post-graduate level $(P=0.006$, Fisher's exact test). No significant differences were found when the other parameters were considered.

\section{Perceived clarity and helpfulness}

Two items aimed at evaluating women's perception of clarity and helpfulness of information received during genetic counselling through a 5-point Likert scale. As shown in Table 2, most women perceived as clear and helpful the information received during counselling, with perception being significantly higher in group B than in group A. Moreover, a statistically significant correlation $\left(\chi^{2}=4.72, \mathrm{df}=1, P=0.030\right)$ was found with the type of IPP undertaken, with women undergoing CVS being more likely to describe the information as extremely/very clear than women undergoing $\mathrm{AC}$ (110/136, 80.9\% versus $61 / 85,71.8 \%)$. Similar results were found for perceived helpfulness, with 99/136 (72.8\%) women undergoing CVS stating the information had been extremely/very helpful if compared with 52/85 (61.2\%) undergoing $\mathrm{AC}\left(\chi^{2}=5.08, \mathrm{df}=1, P=0.024\right)$. After stratifying by age, the differences remained significant only for women under 40 years of age $\left(\chi^{2}=5.36, \mathrm{df}=1, P=0.021 ; \chi^{2}=6.72, \mathrm{df}=1\right.$, $P=0.010$ for clarity and helpfulness, respectively): in this group, 63/76 (82.9\%) undergoing CVS stated the information had been extremely/ very clear and 58/76 (76.3\%) stated it was extremely/very helpful, if compared with 44/63 (69.8\%) and 37/63 (58.7\%), respectively, undergoing AC. No significant differences were found for the other parameters.

Impact on knowledge, risk perception and on expectations toward IPP

As shown in Table 3, the majority of participants $(n=144,65.2 \%)$ reported full or partial previous knowledge of the issues discussed during counselling, with no significant differences between groups $\left(\chi^{2}=0.33, \quad \mathrm{df}=1, \quad P=0.567\right)$, nor in correlation with sociodemographic features, although women declaring no previous knowledge showed a mean gestational age slightly higher than women with previous knowledge (84.2 days versus 79 days) $(\rho=0.165, P=0.016)$. When asked whether they had remaining doubts after counselling, the majority of participants answered 'no' (187; 84.6\%), while $28(12.7 \%)$, answered 'yes', and $6(2.7 \%)$ 'don't know'. Of the 28 stating they had remaining doubts, 16 gave further details: 6 had doubts on the interpretation of laboratory results, 5 failed to clearly understand the procedure of sampling, 3 had not understood the bases for a priori risk estimation, while 2 had not completely understood how chromosomal analysis is carried out. However, women undergoing CVS were more likely to have no remaining doubts $(122 / 134 ; 91.0 \%)$ than women undergoing AC $(65 / 81 ; 80.2 \% ; P=0.035$, Fisher's exact test). After stratifying by age, the differences remained significant only for women under 40 years of age; in this group, 12/61 (19.7\%) women undergoing AC stated to have doubts in comparison with 4/75 (5.3\%) undergoing CVS ( $P=0.015$, Fisher's exact test), which is in agreement with their statements about clarity. The statement about remaining doubts was not significantly influenced by group or sociodemographic features.

To the question whether genetic counselling had changed their perceived risk of having a child with chromosomal abnormalities, 172 women $(77.8 \%)$ reported no changes, 12 (5.4\%) reported increased risk awareness, while 15 women $(6.8 \%)$ stated their perceived risk had increased and $8(3.6 \%)$ stated it had reduced after counselling (one declined IPP upon genetic counselling) (Table 3). A difference was observed by type of counselling $\left(\chi^{2}=15.73, \mathrm{df}=4, P=0.003\right)$ : an unmodified risk perception was reported by a higher rate of women undergoing group counselling (group B) in comparison with those undergoing an individual session (86.5\% versus $70.9 \%$ ); in particular, among the latter (group A), 5.1\% experienced a reduction of perceived risk in comparison with $1.9 \%$ of the former. In addition, a significant difference existed by education ( $P=0.017$, Fisher's exact test): women of postgraduate level were more likely to report a change of their perceived risk in comparison with women of undergraduate level (27/134, 20.1\% versus 10/87, 11.5\%). Moreover, a significant lower rate of risk perception change $(P=0.033$, Fisher's exact test) was 
Table 3 Perceived impact of genetic counselling in women undergoing individual (group A) and group (group B) counselling

\begin{tabular}{|c|c|c|c|c|}
\hline & All $(\mathrm{n}=221)$ & Group $A(n=117)$ & Group $B(\mathrm{n}=104)$ & $\mathrm{P}$ value \\
\hline \multicolumn{5}{|l|}{ Baseline reported knowledge } \\
\hline \multicolumn{5}{|c|}{ Had you previous knowledge of the issues discussed during counselling? } \\
\hline Partially & $17(7.7 \%)$ & $10(8.5 \%)$ & $7(6.7 \%)$ & \multirow[t]{3}{*}{$0.567^{\mathrm{a}, \mathrm{b}}$} \\
\hline No & $70(31.7 \%)$ & $34(29.1 \%)$ & $36(34.6 \%)$ & \\
\hline Don't know & $7(3.2 \%)$ & $5(4.3 \%)$ & $2(1.9 \%)$ & \\
\hline No change & $172(77.8 \%)$ & $82(70.1 \%)$ & $90(86.5 \%)$ & \multirow{5}{*}{$0.003^{c}$} \\
\hline Increased awareness & $12(5.4 \%)$ & $7(6.0 \%)$ & $5(4.8 \%)$ & \\
\hline Increased perceived risk & $15(6.8 \%)$ & $8(6.8 \%)$ & $7(6.7 \%)$ & \\
\hline Reduced perceived risk & $8(3.6 \%)$ & $6(5.1 \%)$ & $2(1.9 \%)$ & \\
\hline Unspecified change & $14(6.3 \%)$ & $14(12.0 \%)$ & 0 & \\
\hline \multicolumn{5}{|c|}{ Impact on expectations toward IPP } \\
\hline Don't know & $1(0.5 \%)$ & 0 & $1(1.0 \%)$ & $0.824^{d, t}$ \\
\hline \multicolumn{5}{|l|}{ If yes: } \\
\hline Increased awareness of diagnostic limits & $14 / 22(63.6 \%)$ & $6(54.5 \%)$ & $8(72.7 \%)$ & \multirow[t]{2}{*}{$0.659^{d}$} \\
\hline Increased awareness of the risk of foetal loss & $8 / 22(36.4 \%)$ & $5(45.5 \%)$ & $3(27.3 \%)$ & \\
\hline Reassurance & $6 / 22(27.3 \%)$ & $4(36.4 \%)$ & $2(18.2 \%)$ & $0.635^{d}$ \\
\hline Increased worry & $16 / 22(72.7 \%)$ & $7(63.6 \%)$ & $9(81.8 \%)$ & \\
\hline
\end{tabular}

${ }^{a}$ Kruskal-Wallis one-way analysis of variance by ranks.

b'Don't know' answers were excluded from the analysis.

cPearson chi-squared test.

dFisher's exact test.

found in women undergoing CVS if compared with those undergoing AC (15/136, 11.0\% versus 22/85, 25.9\%). No significant differences were observed for the other socio-demographic features.

Furthermore, 22 women (10.0\%) stated they had changed their expectations toward IPP after genetic counselling (Table 3), which significantly associated with previous knowledge: 13 of $70(18.6 \%)$ women without previous knowledge had changed their expectations, compared with 5 of 126 (4.0\%) of those reporting previous knowledge $\left(\chi^{2}=11.26, \mathrm{df}=1, P=0.001\right)$. There were no significant differences considering group and socio-demographic features.

\section{Preference between individual and group genetic counselling}

One hundred and forty women $(63.3 \%)$ reported to be satisfied about the type of counselling (individual or group) received, $52(23.5 \%)$ would have preferred the other type of counselling while $29(13.1 \%)$ did not express a preference. Within women who expressed a preference, $127 / 164(77.4 \%)$ of those without doubts were satisfied about the type of counselling received, compared with 10/22 (45.5\%) of those with remaining doubts $(P=0.003$, Fisher's exact test). No significant correlations with socio-demographic features were observed.

Among the 192 women expressing a preference between individual or group approach, $101(52.6 \%)$ preferred/would have preferred individual genetic counselling, while 91 (47.4\%) preferred/would have preferred group genetic counselling: mean gestational age of those preferring individual counselling was 78.7 days, compared with 83.1 days for women expressing preference for group counselling $\left(\chi^{2}=3.88, \mathrm{df}=1, P=0.049\right)$. There were no significant correlations with the other parameters.
Involvement of partner and other family members

Another item explored the presence of the partner at the counselling session. One hundred and fourteen women (51.6\%) reported that the partner had attended the counselling session, whereas the partners of 107 women $(48.4 \%)$ did not attend. The large majority $(98.2 \%)$ of women attending together with the partner stated that the partner agreed with the woman's opinion about the counselling session. An explanation for partner's non-attendance was given by 101 of 107 women: $84(83.2 \%)$ stated he wished to but was not able to attend; 9 (8.9\%) had previously agreed with the partner about IPP and did not think there was the need for him to participate; 5 (5.0\%) had not involved the partner, while $3(2.9 \%)$ stated that the partner was not interested in attending. A significant difference was found between groups, with partners attending reported by 68/117 (58.1\%) women of group A, whereas by $46 / 104(44.2 \%)$ group B participants $(P=0.044$, Fisher's exact test). Younger ( $<40$ years), if compared with older $(\geq 40$ years), women were significantly more likely to attend the counselling session with the partner (80/139, 57.6\% versus 34/82, 41.5\%; $P=0.026$, Fisher's exact test). A difference was also found for education level, with 75/134 (56.0\%) graduated and post-graduated women attending alone, compared with $32 / 87$ (36.8\%) women with undergraduate education $\left(\chi^{2}=7.14, \mathrm{df}=1, P=0.008\right)$. No association was found with other variables.

Ninety-seven women $(43.9 \%)$ stated they had shared the information received with relatives. The reason most frequently reported (43 women; $44.3 \%$ ) was to provide other family members with helpful information; 32 women were seeking reassurance (33.0\%), 17 (17.5\%) had been asked by their relatives, while 5 (5.2\%) did not give explanations for sharing. The women's choice to share/not to share within the family correlated with the impact of counselling on 
expectations about IPP: $16 / 22(72.7 \%)$ of women who had changed their expectations shared the information, compared with $81 / 198$ (40.9\%) of those who had not changed their expectations $(P=0.006$, Fisher's exact test). No differences were found by group and sociodemographic features.

\section{DISCUSSION}

The first relevant finding of the study is that the majority of participants $(67.4 \%)$ reported AMA as the main reason (the only reason for $46.2 \%$ of the overall cohort) to undergo IPP: in particular, $75.6 \%$ of women aged 40 years and older gave this reason. The preference of older women for IPP, rather than for non-invasive techniques, is consistent across different countries, as recent studies show: among Italian women of AMA attending for prenatal diagnosis, $88.2 \%$ opted for IPP; ${ }^{3}$ the vast majority of both Italian and Israeli women of AMA with normal Down Syndrome screening results decided to undergo AC anyway; ${ }^{15,16}$ a direct correlation was observed between increasing age and $\mathrm{AC}$ uptake rate among Chinese women of AMA. ${ }^{17}$ In any case, the idea that AMA itself represents an absolute indication for IPP rather than for non-invasive screening seems deeply rooted in our society, as is also demonstrated by referrals by gynaecologists, with $12.7 \%$ of our study participants reporting that the choice to undergo IPP was due, mainly or exclusively, to the gynaecologist's recommendation; this motivation was more frequently reported by less educated women, who, probably, are more likely to completely rely on physicians' suggestions. Therefore, it can be argued that the attempt to reduce IPP uptake and promote non-invasive techniques would require a cultural change, which might be pursued through educational efforts directed to both health professionals and target population: for the latter, the role of genetic counselling is crucial. In our study, the majority of participants described the information received during counselling as clear and helpful, and only $12.7 \%$ had remaining doubts after counselling, which, however, generally concerned questions falling out the purpose of counselling (such as laboratory procedures). Although this may be regarded as a positive outcome of counselling, the actual impact on perceived risk and decisions seems limited. Indeed, only $16.7 \%$ of participants reported their perceived risk of foetal anomalies had changed and only $10.0 \%$ stated that their expectations about IPP had changed after counselling (for the majority of whom in terms of increased awareness of the diagnostic limits of the analysis); only one woman eventually declined IPP. Therefore, IPP uptake rate is as high as 99.5\%; this may be explained by the fact that counselling session is arranged when women present with IPP request, thus after the choice of IPP has already been made. Such influence of the $a$ priori attitude toward IPP on the actual uptake is in agreement with what previously reported by Vergani and colleagues, ${ }^{15}$ who found that only $8 \%$ of women changed their attitude towards IPP after ultrasound. Another factor that has been claimed to affect uptake is the interval of time between counselling and IPP: utilization of AC was reported to decrease from $93 \%$ when women were counselled on the same day of the procedure to $78 \%$ when counselling was performed earlier $(P<0.05) .{ }^{18}$ In the cohort under study, counselling sessions averagely took place 2 weeks before IPP, thus not confirming an influence of counselling timing in our population. Thus, it appears clear that counselling women who have already made the decision and have booked IPP cannot significantly affect their attitudes. On the other hand, only $10.4 \%$ of women in our study reported the opportunity to make an informed decision about pregnancy as a reason for their choice, suggesting that for most women, the eventual aim of IPP had not been actually taken into account in their decisional process, which underlines the need to improve the pre-test counselling process. An option might be that any newly pregnant woman undergo extensive counselling about the different options of prenatal care, which, anyway, would require the availability of dedicated health professionals or, at least, specific education and clear guidelines for midwives and gynaecologists who see women at the beginning of their pregnancy. As an alternative, women requesting IPP could be offered counselling as the first-line procedure before IPP is arranged (rather than after the appointment has been established), with the counsellor making sure that women/ couples have completed their decisional process by exploring what is the real reason for them to undergo IPP: whether to terminate an abnormal pregnancy, or to prepare themselves to the birth of an affected baby, or to seek reassurance about baby's health, or other. Also this option, however, would imply significant logistic changes.

Regarding satisfaction with counselling, it appeared generally high, as inferred from responses about clarity and helpfulness, as well as from comments added by participants in the questionnaire form. Unexpectedly, however, a difference was observed according to the type of IPP, with women undergoing CVS being significantly more likely to consider the information received as clear and helpful in comparison with women undergoing AC, even though counselling was identical. After stratifying by age, the difference remained significant only for women under 40 years of age. This group is likely to include women whose preference toward CVS could not be accommodated for because priority was given to older women and had to opt for AC, which may have reduced their satisfaction about the whole process, thus leading to lower scores in these answers. The reason why the majority of women requests CVS instead of AC is probably because of their desire of an earlier response.

Concerning the comparison of the two counselling approaches adopted, individual or group, although a slight majority $(52.6 \%)$ expressed a preference for individual counselling, perceived clarity and helpfulness were higher in those undergoing group counselling. This is in line with the results of a randomized trial comparing different prenatal counselling methods, which showed that women and their partners preferred individual genetic counselling, while learned best in group counselling sessions. ${ }^{13}$ Therefore, none of the two approaches has proven superior to the other one in relation to the parameters analysed; in addition, both approaches have been suggested to be similarly effective in identifying risk factors beyond AMA in a previous study, ${ }^{12}$ thus leading to the conclusion that either one can be adopted.

This study has at least two major limitations. First, it has been performed on a retrospective cohort, with a low response rate $(32.2 \%)$, which hampers the conclusion that the findings are actually valid for the entire population of women with AMA undergoing IPP. In fact, it is reasonable to hypothesize that women who had been most satisfied about counselling would be most likely to respond. On the other hand, a retrospective design may have some advantages, in that satisfaction measures have been suggested to be more accurate if assessed retrospectively rather than shortly after counselling. ${ }^{19}$ Secondly, we have evaluated only subjective indicators, such as the perceived impact of counselling, without investigating objective outcomes through validated tools such as knowledge questionnaires and psychometric scales.

In conclusion, although genetic counselling preliminary to IPP is associated to high levels of satisfaction regardless of the approach (group or individual session) adopted, the impact on knowledge, risk perception and decisions appears limited. The reasons underlying the observed diffuse perception that AMA represents an absolute indication to IPP should be explored in more depth through qualitative studies directed to both women and health professionals, in order to 
identify issues to address through targeted educational and counselling interventions.

\section{CONFLICT OF INTEREST}

The authors declare no conflict of interest.

\section{ACKNOWLEDGEMENTS}

We are grateful to all the women who participated for the generosity of their time to help make the study possible. Also, we would like to thank Prof Heather Skirton of Plymouth University, UK, for her stimulating and helpful comments. LG was supported by the Grant FIRB RBNE064RKM 'Genetic Testing and Biobanks: Bioethical Issues in Law and Society' from the Italian Ministry of University and Research; EP was supported by a Grant from the Italian Ministry of Health (Ricerca Finalizzata Esercizio 2007; Sviluppo linee guida per offrire test genetici nelle gravidanze a rischio: implementazione di processi di valutazione dei test genetici).

1 Driscoll DA, Gross S: Clinical practice. Prenatal screening for aneuploidy. N Engl J Med 2009; 360: 2556-2562.

2 Johnson J-A, Tough S: Delayed child-bearing. J Obstet Gynaecol Can 2012; 34: 80-93.

3 Ghi T, Arcangeli T, Ravennati F et al: Prenatal diagnosis versus first-trimester screening of trisomy 21 among pregnant women aged 35 or more. J Matern Fetal Neonatal Med e-pub ahead of print 26 June 2014; 1-5.

4 Zoppi MA, Ibba RM, Putzolu M, Floris M, Monni G: Nuchal translucency and the acceptance of invasive prenatal chromosomal diagnosis in women aged 35 and older. Obstet Gynecol 2001; 97: 916-920.

5 Nicolaides KH: Screening for fetal aneuploidies at 11 to 13 weeks. Prenat Diagn 2011; 31: 7-15.

6 Decreto Legge 10 settembre 1998. Aggiornamento del decreto ministeriale 6 marzo

1995 concernente l'aggiornamento del decreto ministeriale 14 aprile 1984 recante protocolli di accesso agli esami di laboratorio e di diagnostica strumentale per le donne in s. Gazzetta Ufficiale, n.245, 1998.

7 Godino L, Turchetti D, Skirton H: A systematic review of factors influencing uptake of invasive fetal genetic testing by pregnant women of advanced maternal age. Midwifery 2013; 29: 1235-1243.

8 Rubin SP, Malin J, Maidman J: Genetic counseling before prenatal diagnosis for advanced maternal age: an important medical safeguard. Obstet Gynecol 1983; 62: 155-159.

9 Cohn GM, Gould M, Miller RC, Habecker-Green J, Macri CJ, Gimovsky ML: The importance of genetic counseling before amniocentesis. J Perinatol 1996; 16: 352-357, quiz 358-9.

10 Skirton H, Goldsmith L, Jackson L, Lewis C, Chitty L: Offering prenatal diagnostic tests: European guidelines for clinical practice [corrected]. Eur J Hum Genet 2014; 22: 580-586.

11 Dallapiccola B, Agolini E, Morena A et al: Censimento SIGU 2007 delle attività delle Strutture di Genetica Medica. Analysis, 4/5. 2009.

12 Pompilii E, Astolfi G, Calabrese 0 et al: Prenatal genetic counseling referrals for advanced maternal age: still room for improvement. Prenat Diagn 2014; 34: 71-74.

13 Hunter AGW, Cappelli M, Humphreys L et al: A randomized trial comparing alternative approaches to prenatal diagnosis counseling in advanced maternal age patients. Clin Genet 2005; 67: 303-313.

14 O'Cathain A, Murphy E, Nicholl J: Why and how, mixed methods research is undertaken in health services research in England: a mixed methods study. BMC Health Serv Res 2007; 7: 85.

15 Vergani $P$, Locatelli A, Biffi $A$ et al: Factors affecting the decision regarding amniocentesis in women at genetic risk because of age 35 years or older. Prenat Diagn 2002; 22: 769-774.

16 Grinshpun-Cohen J, Miron-Shatz T, Ries-Levavi L, Pras E: Factors that affect the decision to undergo amniocentesis in women with normal Down syndrome screening results: it is all about the age. Health Expect e-pub ahead of print 12 May 2014.

17 Qi Q, Jiang Y, Zhou X, Liu J, Yin J, Bian X: Genetic counseling, prenatal screening and diagnosis of Down syndrome in the second trimester in women of advanced maternal age: a prospective study. Chin Med J (Engl) 2013; 126: 2007-2010.

18 Lorenz RP, Botti JJ, Schmidt CM, Ladda RL: Encouraging patients to undergo prenatal genetic counseling before the day of amniocentesis. Its effect on the use of amniocentesis. J Reprod Med 1985; 30: 933-935.

19 Clarke A, Parsons E, Williams A: Outcomes and process in genetic counselling. Clin Genet 2008; 50: 462-469. 